\title{
Mono- versus polyaxial locking plates in distal femur fractures: a prospective randomized multicentre clinical trial
}

\author{
Marc Hanschen • Ina M. Aschenbrenner • Kai Fehske • Sonja Kirchhoff • \\ Leonhard Keil • Boris M. Holzapfel • Sebastian Winkler • Bernd Fuechtmeier • \\ Rainer Neugebauer • Sven Luehrs • Ulrich Liener • Peter Biberthaler
}

Received: 10 October 2013 / Accepted: 15 November 2013 / Published online: 11 December 2013

(C) Springer-Verlag Berlin Heidelberg 2013

\begin{abstract}
Purpose Treatment of complex fractures of the distal femur utilizing monoaxial locking plates (e.g. Less Invasive Stabilisation System, LISS ${ }^{\circledR}$, Synthes) is considered to be superior to conventional plating systems. Due to the limitation that the thread forces the screw into pre-determined positions, modifications have been made to allow screw positioning within a range of $30^{\circ}$ (Non Contact Bridging, $\mathrm{NCB}^{\circledR}$-DF, Zimmer). For the first time, this multicenter prospective randomized clinical trial (RCT) investigates the outcome of LISS $^{\circledR}$ vs. NCB ${ }^{\circledR}$-DF treatment following complex fractures of the distal femur.
\end{abstract}

M. Hanschen $(\bowtie) \cdot$ I. M. Aschenbrenner • P. Biberthaler Department of Trauma Surgery, Klinikum rechts der Isar, Technical University Munich, Ismaninger Strasse 22, 81675 Munich, Germany e-mail: Marc.Hanschen@mri.tum.de

K. Fehske $\cdot$ B. M. Holzapfel

Department of Trauma, Hand, Plastic and Reconstructive Surgery, University Clinics of Wuerzburg, Oberduerrbacher Str. 6,

97080 Wuerzburg, Germany

\section{S. Kirchhoff}

Department of Clinical Radiology, Ludwig-Maximilians-University, Nussbaumstr. 20, 80336 Munich, Germany

L. Keil

Department of Trauma and Orthopaedic Surgery,

Ludwig-Maximilians-University, Nussbaumstr. 20, 80336 Munich, Germany

S. Winkler $\cdot$ B. Fuechtmeier $\cdot$ R. Neugebauer Department of Trauma and Orthopaedic Surgery, Hospital Barmherzige Brueder, Pruefeninger Str. 86, 93049 Regensburg, Germany

S. Luehrs $\cdot$ U. Liener

Department of Trauma, Hand, Plastic and Reconstructive Surgery, University of Ulm, Albert-Einstein-Allee 23, 89081 Ulm, Germany
Methods Since June 2008, 27 patients with a fracture of the distal femur (AO ASIF 33-A-C and periprosthetic fractures) were enrolled in this study by four university trauma centres in southern Germany. Clinical (e.g. range of motion, Oxford knee score, Tegner score) and radiological (e.g. axis deviation, secondary loss of realignment) follow-ups were conducted one and six weeks, as well as three, six, and 12 months after the operation.

Results This study comprises data of 27 patients ( 8 male, 19 female; $15 \mathrm{NCB}^{\circledR}$-DF, 12 LISS $^{\circledR}$ ). Polyaxial osteosynthesis using the $\mathrm{NCB}^{\circledR}$ system tended to result in better functional knee scores and a higher range of motion. Interestingly, fracture union tended to be more rapid using the polyaxial plating system.

Conclusions We present the analysis of a multicenter prospective RCT to compare the monoaxial LISS ${ }^{\circledR}$ vs. the polyaxial $\mathrm{NCB}^{\circledR}$-DF treatment following complex fractures of the distal femur. $\mathrm{NCB}^{\circledR}$-DF treatment tended to result in better functional and radiological outcomes than LISS ${ }^{\circledR}$ treatment. Level of Evidence Level I

Keywords Monoaxial plating $\cdot$ Polyaxial plating $\cdot$ Locked plate osteosynthesis $\cdot$ Distal femur fracture $\cdot$ Randomized clinical trial

\section{Introduction}

Distal femur fractures constitute 4-7 \% of all femur fractures [1]. The occurrence is bimodal, i.e. most of the younger patients sustain a high energy trauma (e.g. motor vehicle accident), whereas older patients with substantial osteoporosis usually sustain a lower energy trauma [2]. The treatment of complex fractures of the distal femur remains to be a challenge due to displacement, articular involvement, delayed union or osteoporosis. Relevant clinical problems may arise concerning 
postoperative functioning and integrity [3]. The goals of surgery include anatomic reduction, especially of the articular surface, axis alignment, gentle tissue handling and stable primary fixation in order to ensure rapid fracture healing with an optimal functional outcome [2].

Albeit treatment of these fractures used to involve bicondylar plate fixation systems, recent studies advocate the use of a unicondylar locking plate system, functioning as an internal fixation system with angular stable junction of screws and plates. This system called "Less Invasive Stabilizing System" (LISS ${ }^{\circledR}$, Synthes Corp., Umkirch, Germany) proved to show excellent results concerning primary and secondary quality criteria (realignment loss, axial deformity, soft tissue damage) [4-6]. The LISS ${ }^{\circledR}$ system is characterized by angular stable locking of screws in the plate. A thread integrated in the plate pre-determines the direction of the fixed screw position. While the fixed connection between screws and plate promotes stability in the system, the higher caliber of LISS ${ }^{\circledR}$ screws leads to a better load distribution. Both factors lead to a lower rate of secondary loosening and screw dislocation [7]. Especially in osteoporotic bones these advantages account for higher stability and reduction of secondary dislocation $[2$, 8]. In addition, implantation of locking plates does not require full contact to the bone, thereby limiting periostal circulation disorders with subsequently impaired bone healing.

Though obvious advantages of LISS ${ }^{\circledR}$ locking plates are apparent as compared to conventional non-angular stable plate/screw systems, there are also disadvantages to be considered. The existing thread forces the plate to rest in one pre-determined position. Albeit LISS ${ }^{\circledR}$ plates are anatomically confected and fit the distal femur very well, the predetermined screw position often leads to positioning of screws in bone areas which intraoperatively have to be considered of minor quality. This may be associated with secondary loss of realignment and loosening of screws. In addition, periprosthetic fractures can only be treated with locking plates by applying mono-cortical screws, as there is no tolerance concerning screw and plate axis relation [9].

Recently, modifications of the thread integrated into the plate have been made to allow the surgeon to choose the screw position within a range of $30^{\circ}$. The chosen position can be locked by application of a screw nut (Non Contact Bridging - Distal Femur $\mathrm{NCB}^{\circledR}$-DF, Zimmer Corp.). The system has already been approved and is used in clinical practice.

This novel system may contribute to improvements in the treatment of complex distal femur fractures. Up to now, only utilization and biomechanical observations have been published [10, 11], showing low-risk implantation as compared to similar procedures. Unfortunately, studies comparing the available angular stable plating systems are missing [12]. The objective of this multicenter prospective randomized clinical trial is therefore to analyse the quality of complex distal femur fracture treatment using $\mathrm{NCB}^{\circledR}$-DF plates as compared to using mono-axial LISS ${ }^{\circledR}$ plates.

\section{Patients and methods}

Before initiation of the study, it was approved by the human research ethics committee of the Ludwig-MaximiliansUniversity of Munich (Trial Number 385-07). The trial included 27 patients with fractures of the distal femur, recruited from four level-one university trauma centers (Munich, Ulm, Regensburg, Wuerzburg). Patient recruitment was conducted between 2008 and 2011. Fractures of the distal femur, as defined by the AO-ASIF classification system, were included in this trial as soon as they were identified by the treating surgeon being applicable for locking plate treatment. All type 33-A (11), 33-B (3), and 33-C (7) fractures were included, as well as periprosthetic fractures of the distal femur (6). Patients were randomized according to a randomization plan (Randlist ${ }^{\mathbb{R}}$ ). In order to ensure balanced randomization in all four trauma centers, randomization was performed blockwise. Twelve patients received treatment with the LISS ${ }^{\circledR}$ system (Synthes Corp., Umkirch, Germany), and 15 patients were randomized to receive a $\mathrm{NCB}^{\circledR}$-DF plate (Zimmer Corp., Freiburg, Germany).

Surgical technique The surgical technique was standardized as far as possible prior to the study. All surgeons were experienced specialists and agreed to the following procedure. Depending on the fracture classification, a standardized antero-lateral or additional medial approach was used for the reduction of intra-articular fragments. After temporary fixation of articular fragments using screws, K-wires, or clamps, etc., the condyle block was adjusted to the axis of the femur and the whole leg. Therefore, a thorough reduction of the condyle block towards the distal femur was achieved. Then, the locking plate was adjusted and temporarily fixated using K-wires. After intraoperative fluoroscopy control of the correct plate position and axis of the femur, the plate was fixed using either monoaxial or polyaxial screws. In case of the monoaxial system, additional lag screws were inserted before plate application due to the lack of the lag screw mechanism. All patients received perioperative antibiotics. Postoperatively, physiotherapy was commenced and active range of motion exercises were permitted immediately. Nonweight bearing was recommended for six to eight weeks, followed by partial weight bearing until callus formation was apparent in radiographic follow-up examinations.

Intra- / peri-operative data Intra- and perioperative data were assessed using surgeon's questionnaires. The operative time and intraoperative X-ray time were documented. In addition the size of the implant, skin cut length and need for skin cut extension were evaluated. 
Postoperative clinical follow-up The primary follow-up for each patient was one year. The first postoperative assessment was conducted in the clinical setting, assessments at six weeks as well as three, six, and 12 months postoperatively took place in the outpatient department. Assessment of pain using the visual analog scale and demand on analgesics were documented prospectively during each follow-up. Additionally, clinical outcome measures like range of motion, cruciate ligament stability or collateral ligament stability were documented during each follow-up using standardized scoring sheets. Secondary outcome measurements comprised pre-operative details, operation details and four different postoperative knee scoring systems, the Tegner score [13], the Oxford knee score [14], the Rasmussen score [15], and the Lysholm score [13].

Postoperative radiologic follow-up Primary outcome measurements included standard radiological evaluation and clinical assessment. Postoperative radiographs were evaluated for screw misplacement, secondary loss of reduction, and evidence of delayed union in AP and lateral views. In addition, the radiological part of the Rasmussen score was calculated [15]. Assessment of screw misplacement included investigation for intra-articular and interfragmentary screws. Additionally, screws with tips more than $5 \mathrm{~mm}$ outside of the opposite corticalis were considered as misplaced. Secondary loss of reduction included investigation for fragment angulation and investigation for fragment torsion (in each case scoring as follows: A, none; $\mathrm{B},<10^{\circ} ; \mathrm{C}, 10-20^{\circ} ; \mathrm{D},>20^{\circ}$ ). Union / delayed union was assessed according to the following scoring system based on the phases of bone healing: A, cloudy cortical edges and condensation (granulation phase); B, defined edges, bridging, lamellar bone deposition, cartilage callus formation (reparative phase); $\mathrm{C}$, remodeling to original bone contour (remodeling phase); D, pseudarthrosis. In addition to the above-mentioned analysis, the radiologic part of the Rasmussen score was calculated, comprising information about depression, condylar widening and fragment angulation [15].

Statistics Statistical analysis was conducted using SigmaStat Version 11.0 software (Systat Software, San Jose, CA, USA). Data from the groups were analysed using the chi-squared test for binominal variables and the Student's t-test for continuous parametric variables. The data were plotted as mean values \pm SEM. The significance level was set at $p=0.05$.

\section{Results}

Epidemiological data There were no statistically significant differences in patient characteristics or the injury type (Table 1). The mean age was 63.9 and 73.1 years for LISS ${ }^{\circledR}$ and $\mathrm{NCB}^{\circledR}$ patients. Falls from heights below 2 metres and
Table 1 Patient and injury characteristics

\begin{tabular}{lll}
\hline Characteristics & $\operatorname{LISS}^{\circledR}(n=12)$ & $\mathrm{NCB}^{\circledR}(n=15)$ \\
\hline Mean age (years) & 63.9 & 73.1 \\
Sex (males : females) & $3: 9$ & $5: 10$ \\
AO classification & & \\
33-A & 5 & 6 \\
33-B & 1 & 2 \\
33-C & 5 & 2 \\
Periprosthetic & 1 & 5 \\
Trauma characteristics & & \\
Motor vehicle accident & 3 & 2 \\
Falls from stairs & 0 & 2 \\
Falls $>2$ m height & 0 & 0 \\
Falls $<2$ m height & 8 & 10 \\
Other & 1 & 1 \\
Soft tissue injury & & 2 \\
Open & 3 & 1 \\
Gustilo I & 1 & 0 \\
Gustilo II & 2 & 0 \\
Gustilo III & 0 & 1 \\
Not specified & 0 & 0 \\
Closed & 9 & \\
Tscherne 0 & 0 & \\
Tscherne I & 0 & \\
Tscherne II & 8 & \\
Tscherne III & & \\
Not specified & & \\
\hline & & \\
\hline
\end{tabular}

A total of 27 patients, presenting with a fracture of the distal femur (AOtype 33), were recruited to this multicenter study. Patients were randomized for treatment with monoaxial LISS ${ }^{\circledR}$ (Less Invasive Stabilisation System) and polyaxial NCB ${ }^{\circledR}$-DF (Non-Contact Bridging Distal Femur) treatment. There were no statistically significant differences in patient demographics or injury characteristics between the groups

motor vehicle accidents were the most common causes for distal femur fractures in both groups.

Intra- / perioperative data Peri-operative data were assessed utilizing surgeon's questionnaires (Table 2). Intra-operative details such as the size of the implant, the size of the skin cut and need for arthroscopy or skin cut extension were comparable between the groups, thus showing comparable invasiveness of the surgery performed in both groups. The mean operative time tended to be higher using the $\mathrm{NCB}^{\circledR}$ plating system $\left(\mathrm{NCB}^{\circledR} 141.9 \mathrm{~min}\right.$ vs. LISS $\left.{ }^{\circledR} 134.1 \mathrm{~min}\right)$. Though allowing positioning of screws within a range of $30^{\circ}$, the mean intra-operative X-ray time was significantly lower in the group using the $\mathrm{NCB}^{\circledR}$ plating system $(103.3 \mathrm{~s})$ as compared to the LISS $^{\circledR}$ plating system $(188.9 \mathrm{~s}$ ) (Table 2).

Postoperative clinical follow-up Following inclusion to this trial, patient data were acquired in a follow-up of 12 months. 
Table 2 Perioperative data

\begin{tabular}{llll}
\hline Perioperative data & $\begin{array}{l}\text { LISS }^{\circledR} \\
(n=12)\end{array}$ & $\begin{array}{l}\mathrm{NCB}^{\circledR} \\
(n=15)\end{array}$ & $P$-value \\
\hline Mean operative time [minutes] & 134.1 & 141.9 & 0.71 \\
Mean intraoperative x-ray time [seconds] & 188.9 & 103.3 & 0.35 \\
Mean skin cut length [cm] & 9.6 & 10.4 & 0.68 \\
Need for skin cut extension & 0 & 1 & NA \\
Mean size of implant [holes] & 9.3 & 10.1 & 0.48 \\
Intraoperative arthroscopy & 0 & 0 & NA \\
Surgical complications & & & \\
$\quad$ Wound infection & 0 & 0 & NA \\
$\quad$ Peroneal lesions & 0 & 0 & NA \\
Compartment syndrome & 0 & 0 & NA \\
\hline
\end{tabular}

Follow-up analysis of 27 patients following distal femur fracture undergoing surgery with monoaxial (LISS ${ }^{\circledR}$, Less Invasive Stabilisation System) vs. polyaxial $\left(\mathrm{NCB}^{\circledR}\right.$, Non-Contact Bridging) plating systems included assessment of peri-operative data. As compared to the LISS ${ }^{\circledR}$ system, $\mathrm{NCB}^{\circledR}$ plating was accompanied by a significantly lower intraoperative $\mathrm{X}$-ray time. In contrast, $\mathrm{NCB}^{\circledR}$ plating tended to be associated with a higher mean operative time. Besides, there were no other significant differences detected in the peri-operative data. $N A$ not applicable

This included assessment of primary clinical and radiologic data, as well as secondary clinical details. Clinical follow-up included documentation of swelling, redness, joint effusion, delay in wound healing, crepitation, and atrophy of the M. vastus lateralis. We did not see any significant differences between the groups in these clinical parameters. In addition, no significant differences were seen in postoperative pain, as assessed using a visual analogue scale (VAS). Furthermore, the use of analgesics was comparable, and no significant differences could be observed.

Clinical outcome measurements included the assessment of clinical parameters such as the range of motion, cruciate ligament and collateral ligament stability, extension deficit and knee extension strength, as well as meniscal pathology. Interestingly, the flexion of the knee tended to be higher following $\mathrm{NCB}^{\mathrm{DF}}{ }^{\circledR}$ treatment as compared to LISS ${ }^{\circledR}$ treatment, which can be seen in Fig. 1. No significant differences could be observed concerning postoperative extension deficit or knee extension strength. Furthermore, no significant differences were documented concerning ligament stability (cruciate ligaments and collateral ligaments) or meniscal pathology. Clinical scores were included to further characterize the outcome in the follow-up. While pain and functionality are being reflected by the Lysholm score and Rasmussen score, the Oxford knee score provides information about pain and daily life activity, and the Tegner score about pain and sports activity. Interestingly, scores at six weeks and three months showed lower results for the $\mathrm{NCB}^{\circledR}$-DF plating system. In contrast, in the six months follow-up the $\mathrm{NCB}^{\circledR}$-DF plating system tended to result in higher scores as compared to the LISS $^{\circledR}$ system (Table 3).
Postoperative radiologic follow-up Representative X-ray follow-up can be seen in Fig. 2, where pre-operative documentation as well as postoperative follow-up documentation in a case of $\mathrm{NCB}^{\circledR}$-DF treatment is shown. Radiologic data were assessed by a radiologist, X-rays of the postoperative and the follow-up examinations (six weeks, three, six, and 12 months) were analysed. Postoperative X-rays were investigated for screw misplacement. Following LISS ${ }^{\circledR}$ and $\mathrm{NCB}^{\circledR}$ plating of the distal femur, we did not see any intra-articular screw misplacement. Interfragmentary screw misplacement was detected in one patient following $\mathrm{NCB}^{\circledR}$-DF plating. Secondary loss of reduction was assessed by measuring fragment angulation and fragment torsion. No significant differences were seen in the two groups. In contrast, in this study bone healing tended to show differences between the groups. Bone healing was assessed using a score reflecting the phases of bone healing as described above (A, granulation phase; B, reparative phase; $\mathrm{C}$, remodeling phase; $\mathrm{D}$, pseudarthrosis). Following $\mathrm{NCB}^{\circledR}$-DF plating, bone healing tended to be more rapid as compared to LISS ${ }^{\circledR}$ plating (Fig. 3, Panel a). In addition to the above-mentioned radiologic parameters, the Rasmussen score was calculated to further characterize the radiologic outcome. No significant changes were detected between the groups, as can be seen in Fig. 3, Panel b.

\section{Discussion}

Due to the risk of displacement, articular involvement or delayed union, treatment of complex fractures of the distal

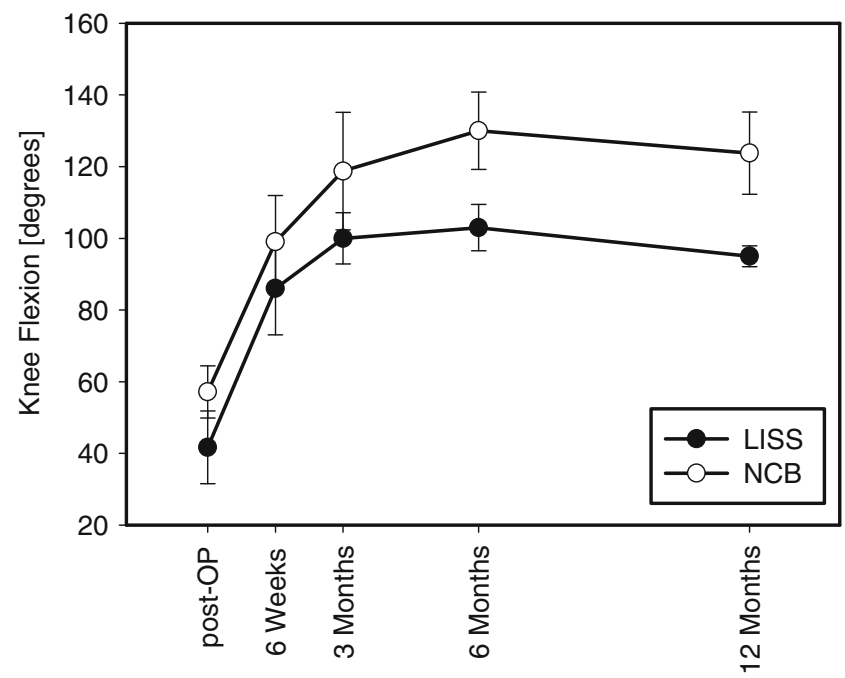

Fig. 1 Knee flexion. Clinical examination included the assessment of the postoperative range of motion. Displayed is the one-year follow up of knee flexion following distal femur fracture and plating with the monoaxial LISS $^{\circledR}$ - vs. polyaxial $\mathrm{NCB}^{\circledR}$-DF-plating system. As compared to the LISS $^{\circledR}$ system, flexion tended to be higher following $\mathrm{NCB}^{\circledR}$-DF-system osteosynthesis. This observation did not reach statistical significance (six months, $p=0.077 ; 12$ months, $p=0.074$ ); data given as mean \pm SEM 
Table 3 Clinical scores

\begin{tabular}{llllll}
\hline Scoring system & $\begin{array}{l}\text { Plating } \\
\text { system }\end{array}$ & Six weeks & $\begin{array}{l}\text { Three } \\
\text { months }\end{array}$ & $\begin{array}{l}\text { Six } \\
\text { months }\end{array}$ & $\begin{array}{l}12 \\
\text { months }\end{array}$ \\
\hline $\begin{array}{l}\text { Oxford knee } \\
\text { score }\end{array}$ & LISS & $28.5 \pm 9.5$ & $28 \pm 2$ & $23.3 \pm 2.7$ & NA \\
Rasmussen & NCB & $23.3 \pm 5.4$ & $22.2 \pm 3.7$ & $31.8 \pm 3.7$ & $31.6 \pm 3.2$ \\
$\quad$ score & NCB & $20.4 \pm 2.9$ & $20.5 \pm 3.3$ & $25 \pm 1.1$ & $22.8 \pm 1.4$ \\
Lysholm score & LISS & $64 \pm 12$ & $67 \pm 10$ & $55 \pm 14$ & NA \\
& NCB & $49.5 \pm 15.2$ & $44 \pm 5$ & $63 \pm 11.2$ & $64.8 \pm 4.4$ \\
Tegner score & LISS & 0 & $1 \pm 1$ & $0.7 \pm 0.3$ & NA \\
& NCB & $1.3 \pm 0.5$ & $0.4 \pm 0.2$ & $1.5 \pm 0.5$ & $2.6 \pm 0.7$ \\
\hline
\end{tabular}

Four different clinical scores were assessed to monitor the outcome of patients following distal femur fractures undergoing surgery with monoaxial LISS ${ }^{\circledR}$ vs. polyaxial $\mathrm{NCB}^{\circledR}$ plating systems. As compared to the LISS ${ }^{\circledR}$ system, osteosynthesis with the $\mathrm{NCB}^{\circledR}$ plating system tended to result in higher functional scores after six months. This observation did not reach the level of significance. $N A$ not applicable

femur remains to be a challenge to the surgeon. In addition, the increasing incidence of osteoporosis, characterized by decreased mineral content, changes in bone architecture and thinner cortices [16], contribute to this challenge. A recent advance in the treatment of complex fractures of the distal femur has been the introduction of the monoaxial locked plate osteosynthesis called LISS ${ }^{\circledR}$ ('less invasive stabilization system', Synthes Corp.). Due to the angular stable locking of the screws in the plate, the osteosynthesis acts as an 'internal fixator'. The LISS ${ }^{\circledR}$ system showed excellent results in primary and secondary outcome criteria following complex distal femur fractures [4-6]. It has been identified though, that the predetermined position of the screws might be a potential drawback to this system. In contrast to the LISS $^{\circledR}$ system, the $\mathrm{NCB}^{\circledR}$-DF plate ('non-contact bridging-distal femur', Zimmer Corp.) allows the surgeon to choose screw positioning within a range of $30^{\circ}$. Unfortunately, studies comparing these locking plate systems applied to the distal femur are missing so far. This is the first randomized clinical trial to assess whether mono-(LISS ${ }^{\circledR}$ ) versus polyaxial $\left(\mathrm{NCB}^{\circledR}-\mathrm{DF}\right)$ locking screw osteosynthesis has an impact on primary and secondary outcome parameters following complex fractures of the distal femur.

Non-locked plate osteosynthesis depends on frictional force, creating a load transfer from the bone to the plate. The construct remains stable as long as the frictional force exceeds

Fig. 2 Radiologic follow-up. The follow-up for each patient was one year, including postoperative evaluation of radiographs, after six weeks and three, six, and 12 months. Exemplary radiographs of a 41-year-old patient are shown, who presented with an AO-type 33-B fracture of the right distal femur following motor vehicle accident. Preoperative X-ray (a) and postoperative images (b) following $\mathrm{NCB}^{\circledR}$-DF plating are shown. Follow-up included radiographic examination at three (c), six (d), and 12 months (e) postoperatively. In addition, radiographs following removal of the $\mathrm{NCB}^{\circledR}$-DF plate after 18 months are shown (f)
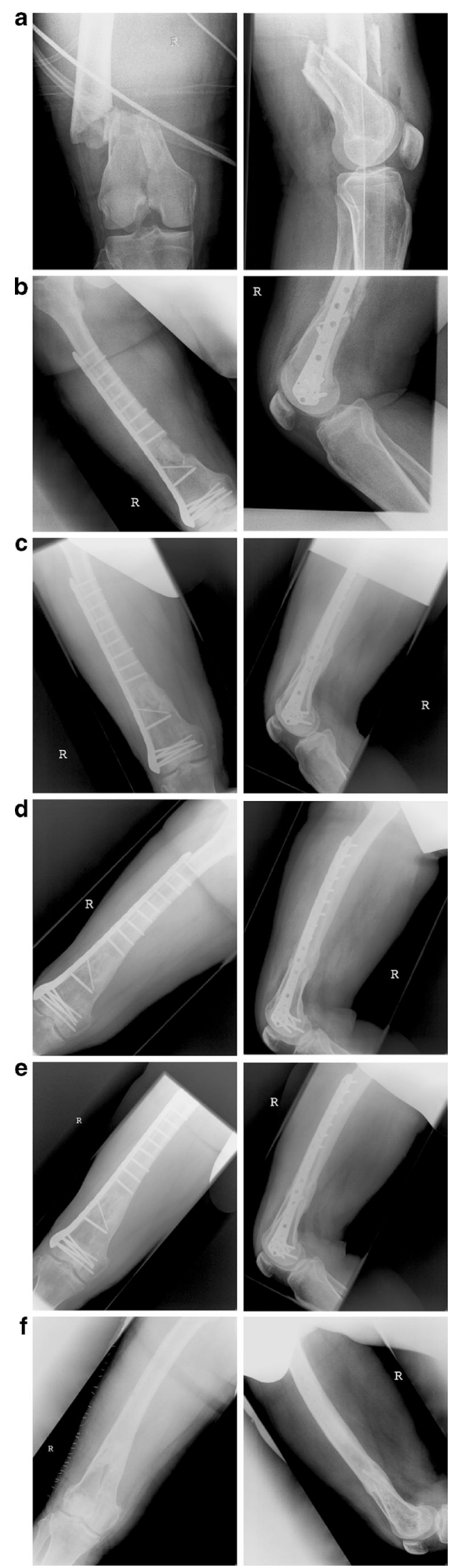
a

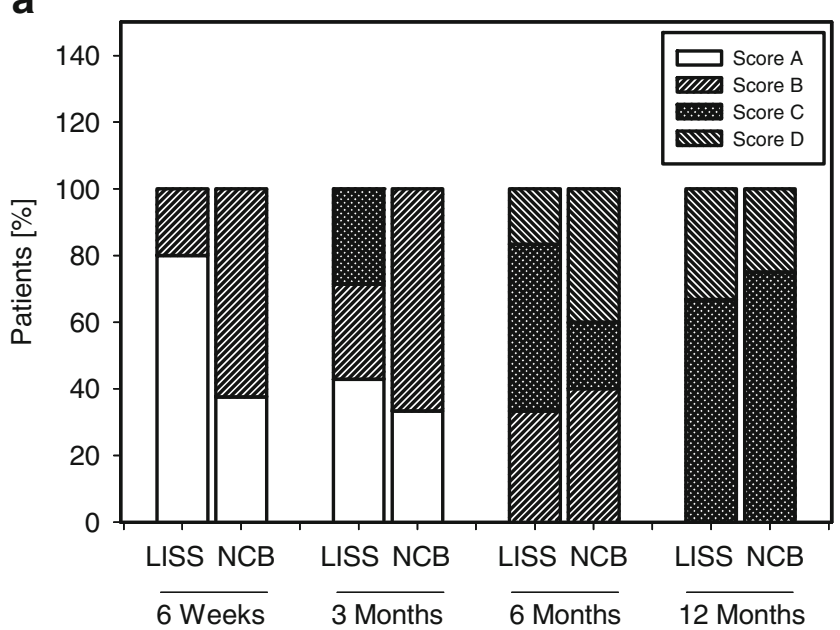

b

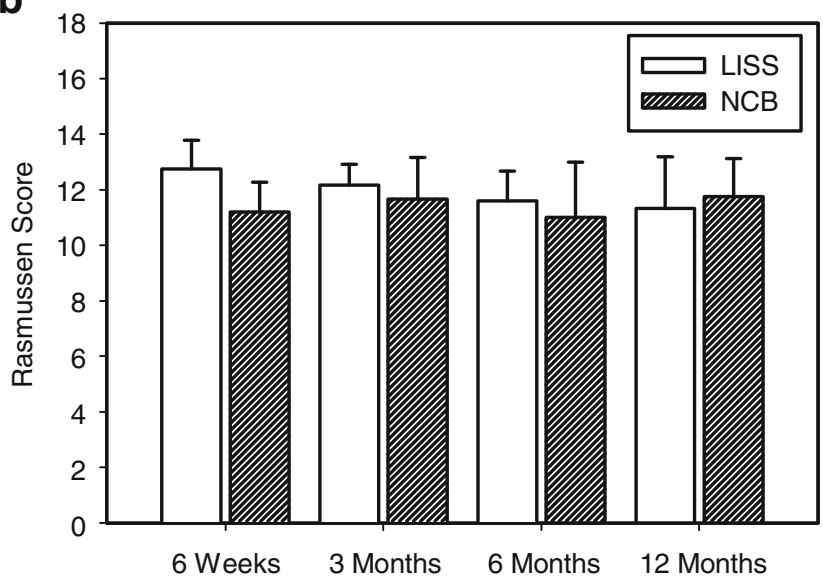

Fig. 3 Radiologic follow-up included assessment of union and the radiological part of the Rasmussen score. During the one-year followup following monoaxial (LISS ${ }^{\circledR}$ ) vs. polyaxial plating $\left(\mathrm{NCB}^{\circledR}-\mathrm{DF}\right)$ of distal femure fractures, radiological data were obtained. Progress of union (Panel a) was analysed using a scoring system (score A: cloudy condensation [granulation phase]; score B: bridging and cartilage callus formation [reparative phase]; score $\mathrm{C}$ : remodeling to original bone contour [remodeling phase]; score D: pseudarthrosis). Osteosynthesis with the $\mathrm{NCB}^{\circledR}$-DF plating system tended to result in a more rapid union of the fracture. The radiological part of the Rasmussen score (Panel b) was assessed during the follow-up and did not show any significant differences between the groups

the applied load [17]. In case of construct instability, the screws begin to toggle resulting in screw pull-out $[17,18]$. High compression forces can lead to disturbances of periostal blood circulation, associated with delayed union and non-union [19]. In contrast, locked plate osteosynthesis provides high primary stability functioning as an internal fixation device not requiring frictional force between the implant and the bone.

Previous studies have tried to delineate differences between mono- versus polyaxial locking plates. Biomechanical studies have been conducted in the past to test whether monoaxial and polyaxial screw-plate designs are comparable. In a biomechanical study using synthetic distal femurs, no differences in stiffness, load to failure and mode of failure were detected between the LISS ${ }^{\circledR}$ and $\mathrm{NCB}^{\circledR}$-DF groups [10]. In a biomechanical study performed in formalin-fixed proximal humerus bone, the same results in the cyclic tests, the fatigue tests and the crash tests were found [20]. In a randomized prospective study using radiographic evaluation, similar results were detected for secondary varus displacement and screw cut-out using mono- vs. polyaxial angular stable plating of displaced proximal humeral fractures [21]. Using formalin-fixed femurs, the treatment of periprosthetic fractures with LISS ${ }^{\circledR}$ and $\mathrm{NCB}^{\circledR}$ plating was investigated. Though $\mathrm{NCB}^{\circledR}$ plating allowed for bicortical screw fixation in contrast to LISS ${ }^{\circledR}$ plating, no notable differences in osteotomy failure load or amount of motion in the osteotomy gap were detected [22]. Biomechanical studies did not detect differences between mono- versus polyaxial plating systems. According to the manufacturer, the following differences in design between the plating systems exist: $\mathrm{NCB}^{\circledR}$ screws are self-tapping, plates and screws are made of titanium alloy, the plate is available in five, nine, and 13 holes designs $(167,246,324 \mathrm{~mm})$, and the plate thickness is $5.7 \mathrm{~mm}$ (shaft and head). Locking screws are $5.0 \mathrm{~mm}$ in diameter. In contrast, LISS $^{\circledR}$ plates are made of either stainless steel or titanium alloy. The LISS ${ }^{\circledR}$ plate is available in five, seven, nine, 11, 13, 15, 17, and 19 hole designs $(156,196$, $236,376,316,356,296$, and $436 \mathrm{~mm}$ ) and has a plate thickness of $5.6 \mathrm{~mm}$ (shaft) and $2.8 \mathrm{~mm}$ (head). Locking screws are $5.0 \mathrm{~mm}$ in diameter. In contrast to the LISS $^{\circledR}$ system, the $\mathrm{NCB}^{\circledR}$ system allows screws to be inserted as lag screws first, therefore allowing for compression and indirect reduction. Screws may be locked at a fixed angle at any time [23].

In this study, the mean operative time for $\mathrm{NCB}^{\circledR}$-DF osteosynthesis tended to be higher as compared to LISS ${ }^{\circledR}$ osteosynthesis. This is in line with findings in the literature, that locking plates might require time in application [16]; polyaxial screw placement and fixation of screws may account for the difference in operative time. In particular, while using the $\mathrm{NCB}^{\circledR}$ system the application of screw nuts can be time consuming. Interestingly, though allowing for polyaxial screw placement, the mean intraoperative X-ray time was significantly lower in the $\mathrm{NCB}^{\circledR}$ group as compared to the LISS $^{\circledR}$ group. This might be due to the above-mentioned differences in plate design, i.e. the $\mathrm{NCB}^{\circledR}$ plate allows for indirect reduction using inserted screws as lag screws first.

Osteosynthesis using the polyaxial $\mathrm{NCB}^{\circledR}$-DF system tended to result in higher knee scores following six months as compared to the LISS ${ }^{\circledR}$ system. In addition, during 12 months follow-up a higher and more rapid restoration of knee flexion was observed in the $\mathrm{NCB}^{\circledR}$-DF group as compared to the LISS ${ }^{\circledR}$ group. At first sight, this observation seems rather contradictory to the expected outcome. Patients following osteosynthesis of the distal femur using the $\mathrm{NCB}^{\circledR}$ DF plate sporadically reported discomfort and pain due to the higher head thickness of $\mathrm{NCB}^{\circledR}$-DF plates as compared to 
LISS $^{\circledR}$ plates. Along with pain and discomfort, the higher thickness of $\mathrm{NCB}^{\circledR}$ plates could potentially affect the integrity of the vastus lateralis muscle and the iliotibial tract. Although the above-mentioned potential drawbacks of the $\mathrm{NCB}^{\circledR}$-DF plate exist and have been reported, superior outcomes in clinical parameters such as flexion capability and knee scores were determined in this study. Observations in the radiologic analysis might account for this better clinical outcome. We observed a more rapid union of the fracture using the $\mathrm{NCB}^{\circledR}{ }_{-}$ DF system as compared to the $\operatorname{LISS}^{\circledR}$ system. Further contributing factors of the superior clinical outcome remain speculative. The $\mathrm{NCB}^{\mathbb{}}$-DF system, although thicker, might cause less tractus irritation due to its optimized anatomic alignment in comparison to the LISS $^{\circledR}$ system. Furthermore, the lag screw mechanism might reduce the distance between bone and $\mathrm{NCB}^{\circledR}$ plate, thereby leading to better plate positioning.

Limitations of this study are the low number of patients included and the heterogeneity of fractures included. In contrast, the high quality of the data due to the collection of data during a 12-month follow-up and the multicenter randomization underline the results presented.

In summary, this is the first multicenter prospective randomized clinical trial to investigate differences in the clinical and radiological outcome following treatment of complex fractures of the distal femur using poly-axial $\mathrm{NCB}^{\circledR}$-DF plates as compared to using mono-axial LISS ${ }^{\circledR}$ plates. Though being demanding in application and technique, the poly-axial $\mathrm{NCB}^{\circledR}$-DF system tends to be associated with a higher functional outcome as compared to the LISS ${ }^{\circledR}$ system. This might be due to the more rapid fracture union, as observed in the radiologic analysis. Further studies will have to focus on the impact of screw positioning on fracture union. The relevance of this study is emphasized by the lack of a comparative study between $\mathrm{NCB}^{\circledR}$-DF and LISS $^{\circledR}$ and the reliance on utilization observations so far.

Acknowledgments The authors thank A. Berglehner, F. Gebhard, R. Meffert, and W. Mutschler for their valuable advice and support.

Conflict of interest $\mathrm{PB}$ is a surgical instructor in AO courses on the LISS $^{\circledR}$-system as well as for the Zimmer institute on the $\mathrm{NCB}^{\circledR}$-system. The entire study was independently conducted and did not receive any financial aid whatsoever.

\section{References}

1. Martinet O, Cordey J, Harder Y, Maier A, Buhler M, Barraud GE (2000) The epidemiology of fractures of the distal femur. Injury 31(Suppl 3):C62-C63

2. Schandelmaier P, Gossling T, Partenheimer A, Krettek C (2002) Distal fractures of the femur. Chirurg 73:1221-1233

3. Kinzl LF (2000) Distal. In: Ruedi TP, Murphy WM (eds) AO Principles of fracture management. Thieme, New York, pp 469-480
4. Partenheimer A, Gosling T, Muller M, Schirmer C, Kaab M, Matschke S, Ryf C, Renner N, Wiebking U, Krettek C (2007) Management of bicondylar fractures of the tibial plateau with unilateral fixed-angle plate fixation. Unfallchirurg 110:675-684

5. Kregor PJ, Stannard J, Zlowodzki M, Cole PA, Alonso J (2001) Distal femoral fracture fixation utilizing the Less Invasive Stabilization System (L.I.S.S.): the technique and early results. Injury 32(Suppl 3): SC32-SC47

6. Cole PA, Zlowodzki M, Kregor PJ (2003) Less Invasive Stabilization System (LISS) for fractures of the proximal tibia: indications, surgical technique and preliminary results of the UMC Clinical Trial. Injury 34(Suppl 1):A16-A29

7. Marti A, Fankhauser C, Frenk A, Cordey J, Gasser B (2001) Biomechanical evaluation of the less invasive stabilization system for the internal fixation of distal femur fractures. J Orthop Trauma 15: 482-487

8. Chakravarthy J, Bansal R, Cooper J (2007) Locking plate osteosynthesis for Vancouver type B1 and type C periprosthetic fractures of femur: a report on 12 patients. Injury 38:725-733

9. Holzapfel BM, Prodinger PM, Hoberg M, Meffert R, Rudert M, Gradinger R (2010) Periprosthetic fractures after total hip arthroplasty: classification, diagnosis and therapy strategies. Orthopade 39:519-535

10. Otto RJ, Moed BR, Bledsoe JG (2009) Biomechanical comparison of polyaxial-type locking plates and a fixed-angle locking plate for internal fixation of distal femur fractures. J Orthop Trauma 23:645-652

11. El-Zayat BF, Zettl R, Efe T, Kruger A, Eisenberg F, Ruchholtz S (2012) Minimally invasive treatment of geriatric and osteoporotic femur fractures with polyaxial locking implants (NCB-DF(R)). Unfallchirurg 115:134-144

12. Hanschen M, Biberthaler P (2013) Mono- versus polyaxial locking plates. Unfallchirurg 116:733-741

13. Tegner Y, Lysholm J (1985) Rating systems in the evaluation of knee ligament injuries. Clin Orthop Relat Res 198:43-49

14. Whitehouse SL, Blom AW, Taylor AH, Pattison GT, Bannister GC (2005) The Oxford knee score; problems and pitfalls. Knee 12:287-291

15. Rasmussen PS (1973) Tibial condylar fractures. Impairment of knee joint stability as an indication for surgical treatment. J Bone Joint Surg Am 55:1331-1350

16. Sommer C, Babst R, Muller M, Hanson B (2004) Locking compression plate loosening and plate breakage: a report of four cases. $\mathrm{J}$ Orthop Trauma 18:571-577

17. Miranda MA (2007) Locking plate technology and its role in osteoporotic fractures. Injury 38(Suppl 3):S35-S39

18. Schutz M, Sudkamp NP (2003) Revolution in plate osteosynthesis: new internal fixator systems. J Orthop Sci 8:252-258

19. Luthi U, Rahn BA, Perren SM (1980) Area of contact between osteosynthesis plate and bone in internal fixation (author's transl). Aktuelle Traumatol 10:131-136

20. Zettl R, Muller T, Topp T, Lewan U, Kruger A, Kuhne C, Ruchholtz S (2011) Monoaxial versus polyaxial locking systems: a biomechanical analysis of different locking systems for the fixation of proximal humeral fractures. Int Orthop 35:1245-1250

21. Ockert B, Braunstein V, Kirchhoff C, Korner M, Kirchhoff S, Kehr K, Mutschler W, Biberthaler P (2010) Monoaxial versus polyaxial screw insertion in angular stable plate fixation of proximal humeral fractures: radiographic analysis of a prospective randomized study. J Trauma 69:1545-1551

22. Konstantinidis L, Hauschild O, Beckmann NA, Hirschmuller A, Sudkamp NP, Helwig P (2010) Treatment of periprosthetic femoral fractures with two different minimal invasive angle-stable plates: biomechanical comparison studies on cadaveric bones. Injury 41 : 1256-1261

23. Roderer G, AbouElsoud M, Gebhard F, Claes L, Aschoff AJ, Kinzl L (2010) Biomechanical investigation of fixed-angle plate osteosynthesis of the proximal humerus. Unfallchirurg 113:133-138 